\title{
Chemical Control of Natural Gas Hydrate
}

\author{
R. N. Abu, L. G. Amah, A. Dulu and Olalekan M. Adeloye
}

\begin{abstract}
The study investigates chemical control of hydrates in pipeline by the application of different chemical substances such as methanol, ethylene glycol, diethylene glycol and triethylene glycol. Aspen Hysys simulator was used to determine hydrate formation temperature based on gas field composition and operating pressure by using Peng-Robinson equation. Similar simulations were carried out with the injection of chemical inhibitors such as methanol, ethylene glycol, diethylene glycol and triethylene glycol. The chemical inhibitors prevent hydrate formation by increasing depression temperature thereby reducing hydrate formation temperature, and thus mitigating against hydrate formation and ensuring constant flow and production of fluid with methanol been the most effective chemical inhibitor based on the hydrate formation temperature reduction trends and analysis.
\end{abstract}

Index Terms - Hydrate formation temperature; chemical inhibitors; gas gravity; temperature depression; Aspen Hysys simulator.

\section{INTRODUCTION}

Gas hydrates composed of water, methane, ethane, propane, isobutene, normal butane, carbondioxide, nitrogen, hydrogensulphide and are crystalline solids also called clathrate. Its structure is polyhedral of hydrogen bonded water molecule. The polyhedral structure form cages that contain at most one of guest(gas) molecule each. The cages are held by an intermolecular force (Vander Waals) between the water(host) molecule and the enclathrated guest(gas) molecule. It is noted that in extreme condition, two guest molecules many enter the same cage [1]. Natural gas hydrates are nonstoichiometric solid substances that are captured in a mesh cage system made up of water molecules and contains low amount of gas molecules. At high pressure and low temperature condition, when hydrate constituents are in contact and coagulate, a solid substance of different crystal structures that possesses high densities than typical fluid hydrocarbons emerge [2]. The hydrate structure is composed of cavities which are formed by hydrogen bond of cluster of cyclic water. The closed ring structure attains stability than the linear cluster as a result of the extra bond of hydrogen [3].

The mechanism of gas hydrate formation is mainly based on two phenomena, the nucleation and growth which have the same process like that of precipitation of salt from solution. The nucleation could be termed as a microscopic phenomenon where gas-water cluster(nuclei) grow and are dispersed until it grows to critical size. This could be homogenous when it occurs spontaneously or heterogeneous when it is induced around impurities. Primary nucleation

Published on December 22, 2016.

R. N. Abu, L. G. Amah, A. Dulu and Olalekan M. Adeloye are with Rivers State University of Science and Technology, Port Harcourt, Nigeria. (e-mail: adeloye.olalekan@yahoo.com) starts without crystal being present while secondary nucleation starts where crystal have grown already.

Induction time is a time the first gas-liquid contact to the first detection of hydrate phase. The induction time was used to predict the nucleation period and it states that, induction time increases dramatically when the driving force for hydrate formation approaches zero [4].

Flow assurance has to do with the risks and problems arising from the challenging properties and behavior of produce hydrocarbons associated fluids and solids. The structured engineering analysis process ensures the utility of the in-depth knowledge of the properties of fluid and thermal hydraulic analysis of the system to develop control strategies for hydrate, wax, asphaltenes and scale [5]. Hydrate growth process is considered to be a combination of three elements; the kinetics of crystal growth at the surface of hydrate, mass transfer component to the growing surface and the heat transfer component away from the growing surface. In growth process, gas reacts with water after the pressure and temperature have being reduced linearly, hence at this stage no hydrate is formed and it is termed induction time. The induction time is understood to be a period of entering to a hydrate forming region and the onset of hydrate formation. Natural gas hydrate is one of the main issues facing the petroleum and gas industry today since its effect have been felt worldwide in the upstream and downstream sector. The associated constraints with natural gas hydrate include blockage of pipeline, blockage of separation facilities and instruments, pressure and flow monitoring errors, reduction in the volume of natural gas transported, increase in pipeline pressure differences and thus damaging the pipe fittings.

Anti-agglomerate method of hydrate control prevents the hydrate from depositing or agglomerating by forming a hydrate sherry which is transported through pipeline and comprise mainly of liquid hydrocarbon [6]. The effect of ethylene-glycol on hydrate formation process was analyzed by considering operating condition of the field before and after injection of glycol. There is increased production from $75.073 \mathrm{MMBtu} /$ day to about $127.827 \mathrm{MMBtu} /$ day, which is $41.2 \%$ of the initial gas production of the field after injecting the field with low dosage ethylene glycol into the production zone. It can therefore be deduced that ethylene glycol acted as an inhibitor since it helps in dissociating hydrate plug from pipe which amounted to increase in production [7].

This study investigates hydrate formation temperature and its inhibition by chemical technique on a gas field in Niger Delta region of Nigeria. Gas gravity approach is used as a result of its effectiveness in quantifying hydrate formation condition for mixture of sweet gas and in determining hydrate formation temperature. The amount of chemical inhibitors required for hydrate formation prevention is estimated by using temperature depression method based on 
the associated assumptions. The application of Aspen Hysys as a useful simulator for hydrate formation temperature and prevention analysis by applying methanol, ethylene glycol, diethylene glycol and triethylene glycol as inhibitors. The effects of these inhibitors on hydrate formation temperature are examined, compared and deductions are made.

TABLE I: FIELD COMPOSITION

\begin{tabular}{|c|c|c|c|c|c|c|c|c|c|c|c|}
\hline Components & $\mathrm{CH}_{4}$ & $\mathrm{C}_{2} \mathrm{H}_{6}$ & $\mathrm{C}_{3} \mathrm{H}_{8}$ & i- $\mathrm{C}_{4} \mathrm{H}_{10}$ & $\mathrm{C}_{4} \mathrm{H}_{10}$ & $\mathrm{i}-\mathrm{C}_{5} \mathrm{H}_{12}$ & $\mathrm{C}_{5} \mathrm{H}_{12}$ & $\mathrm{C}_{6} \mathrm{H}_{14+}$ & $\mathrm{CO}_{2}$ & $\mathbf{N}_{2}$ & Total \\
\hline Mole Fraction(\%) & 95.17 & 2.66 & 0.58 & 0.16 & 0.17 & 0.09 & 0.07 & 0.03 & 0.937 & 0.13 & 100.00 \\
\hline Molecular Weight & 16 & 30.1 & 44.1 & 58.1 & 58.1 & 72.2 & 72.2 & 86 & 44 & 28 & 508.8 \\
\hline $\begin{array}{l}\text { Average } \\
\text { Molecular } \\
\text { Weight }\left(\mathbf{Y}_{\mathrm{i}} \mathbf{M i}\right)\end{array}$ & $\begin{array}{c}15.22 \\
72\end{array}$ & 0.8007 & 0.2558 & 0.0930 & 0.0988 & 0.0650 & 0.0505 & 0.0258 & 0.4122 & 0.0364 & 117.065 \\
\hline
\end{tabular}

TABLE II: GAS FIELD STREAM CONDITION

\begin{tabular}{|c|c|c|c|c|}
\hline \multicolumn{3}{|c|}{ Temperature $\left({ }^{0} \mathrm{C}\right)$} & \multicolumn{2}{|c|}{16.9828} \\
\hline \multicolumn{3}{|c|}{ Pressure (Bar) } & \multicolumn{2}{|c|}{17.2369} \\
\hline \multicolumn{3}{|c|}{ Flow Rate $\left(\mathrm{m}^{3} / \mathrm{h}\right)$} & \multicolumn{2}{|c|}{54.66036} \\
\hline \multicolumn{3}{|c|}{ Free Water Rate (barrel/day) } & \multicolumn{2}{|c|}{6.58} \\
\hline \multicolumn{3}{|c|}{ Comp Mole Frac (Methane) } & \multicolumn{2}{|c|}{0.948301} \\
\hline \multicolumn{3}{|c|}{ Comp Mole Frac (Ethane) } & \multicolumn{2}{|c|}{0.032284} \\
\hline \multicolumn{3}{|c|}{ Comp Mole Frac (Propane) } & \multicolumn{2}{|c|}{0.001594} \\
\hline \multicolumn{3}{|c|}{ Comp Mole Frac (i-Butane) } & \multicolumn{2}{|c|}{0.001694} \\
\hline \multicolumn{3}{|c|}{ Comp Mole Frac (n-Butane) } & \multicolumn{2}{|c|}{0.000897} \\
\hline \multicolumn{3}{|c|}{ Comp Mole Frac (i-Pentane) } & \multicolumn{2}{|c|}{0.000697} \\
\hline \multicolumn{3}{|c|}{ Comp Mole Frac (n-Hexane) } & \multicolumn{2}{|c|}{0.000299} \\
\hline \multicolumn{3}{|c|}{ Comp Mole Frac $\left(\mathrm{CO}_{2}\right)$} & \multicolumn{2}{|c|}{0.009337} \\
\hline \multicolumn{3}{|c|}{ Comp Mole Frac $\left(\mathbf{N}_{2}\right)$} & \multicolumn{2}{|c|}{0.001295} \\
\hline \multicolumn{3}{|c|}{ Comp Mole Frac $\left(\mathrm{H}_{2} \mathrm{O}\right)$} & \multicolumn{2}{|c|}{0.003602} \\
\hline \multicolumn{3}{|c|}{ Hydrate Formation Temp $\left({ }^{0} \mathrm{C}\right)$} & \multicolumn{2}{|c|}{1.095} \\
\hline \multicolumn{3}{|c|}{ Hydrate Formation Pressure (Bar) } & \multicolumn{2}{|c|}{104.180} \\
\hline \multicolumn{5}{|c|}{ TABLE III: INHIBITORS INPUT PARAMETERS } \\
\hline INHIBITOR & M & $\mathrm{X}_{\mathrm{m}}$ & $\mathrm{C}$ & $\mathrm{W}$ \\
\hline $\mathrm{MEOH}$ & 32 & 0.612 & 2335 & 0.02303 \\
\hline EGLYCOL & 62.07 & 0.6423 & 2700 & 0.013869 \\
\hline DEGLYCOL & 106.12 & 0.7231 & 4000 & 0.008848 \\
\hline TEGLYCOL & 150.17 & 0.7634 & 5400 & 0.00642 \\
\hline
\end{tabular}

\section{Methodology}

The compositions of gas field A in the Niger Delta region of Nigeria applicable in this study are shown below.

\section{A. Gas Gravity}

The gas gravity is defined as the ratio of molecular weight of the gas to that of air. This method is best applicable when gas composition is not known and is useful in estimating hydrate formation condition for mixture of sweet gas.

$$
S G=\sum_{i=1}^{n} \frac{y_{i} M_{w i}}{M_{\text {wair }}}
$$

\section{B. Temperature Depression}

This is used to estimate the total amount of inhibitor methanol, ethylene glycol, diethylene glycol and triethylene glycol that is needed to be injected to inhibit hydrate formation. The total amount of inhibitor needed for hydrate inhibition is the amount that is in three phases namely aqueous liquid hydrocarbon, vapour and liquid hydrocarbon. Hammer-Schmidt equation is used to calculate the inhibitor concentration in the aqueous phases based on the assumptions that the effect of inhibitor is independent of pressure, temperature of depression is independent of the nature of hydrate former present and the type of hydrate formed. The Hammer-Schmidt equation is valid for natural gases with methanol concentrations $20-25 \mathrm{wt} \%$ and 60 $70 \mathrm{wt} \%$ for glycol and the equation is expressed as:

$$
\Delta T=\frac{k w}{100(m w)-(m w) w}
$$

\section{Hydrate Formation Temperature}

The hydrate formation temperature was determined from Katz plot curve fit equation at specific gas gravity. For this study, gas gravity of 0.56 was deduced and applicable. The Katz plot equation is expressed thus[8]:

$$
T=13.055 \ln (P)-31.29
$$

\section{Aspen-Hysys Simulator}

The Peng-Robinson equation of state embedded in Hysys simulator is used for the three phase hydrate predictions. The simulator parameters such as pressure, natural gas composition, inhibitors and water content are defined and initiated in the simulator. The first or initial simulation is performed with no inhibitor and the resulting outcome is listed in Table 4 and plotted in figure 1 as reference temperature value for hydrate formation. Subsequently, other simulations were carried out for hydrate formation prevention by using inhibitors such as methanol, ethylene glycol, diethylene glycol and triethylene glycol and the resulting outcomes and plots are shown in tables 5,6,7,8 and figures 2, 3, 4 and 5 respectively.

\section{RESULTS ANALYSIS}

The analysis of the result or outcome of Aspen-Hysys simulator applied in this study are highlighted as follows.

\section{A. Hydrate Formation Temperature with No Inhibitor}

The first simulation study was performed to deduce hydrate formation temperature of gas field A with no inhibitor and the result is shown thus. 
TABLE IV: HYDRATE FORMATION TEMPERATURE WITH NO INHIBITOR

\begin{tabular}{lcc}
\hline State & $\mathbf{P}(\mathbf{B a r})$ & $\mathbf{T}\left({ }^{\mathbf{0}} \mathbf{C}\right)$ \\
\hline $\mathbf{1}$ & 0 & $-3.28 \mathrm{E} 4$ \\
\hline $\mathbf{2}$ & 10 & $-3.28 \mathrm{E} 4$ \\
\hline $\mathbf{3}$ & 20 & 2.41 \\
\hline $\mathbf{4}$ & 30 & 5.97 \\
\hline $\mathbf{6}$ & 40 & 8.42 \\
\hline $\mathbf{7}$ & 50 & 10.51 \\
\hline $\mathbf{8}$ & 60 & 12.21 \\
\hline $\mathbf{9}$ & 70 & 13.61 \\
\hline $\mathbf{1 0}$ & 80 & 14.78 \\
\hline $\mathbf{1 1}$ & 90 & 15.79 \\
\hline $\mathbf{1 2}$ & 100 & 16.66 \\
\hline $\mathbf{1 3}$ & 110 & 17.44 \\
\hline $\mathbf{1 4}$ & 120 & 18.13 \\
\hline $\mathbf{1 5}$ & 130 & 18.76 \\
\hline $\mathbf{1 6}$ & 140 & 19.33 \\
\hline $\mathbf{1 7}$ & 150 & 19.85 \\
\hline $\mathbf{1 8}$ & 160 & 20.33 \\
\hline $\mathbf{1 9}$ & 170 & 20.78 \\
\hline $\mathbf{2 0}$ & 180 & 21.20 \\
\hline $\mathbf{2 1}$ & 190 & 21.60 \\
\hline & 200 & 21.97 \\
\hline
\end{tabular}

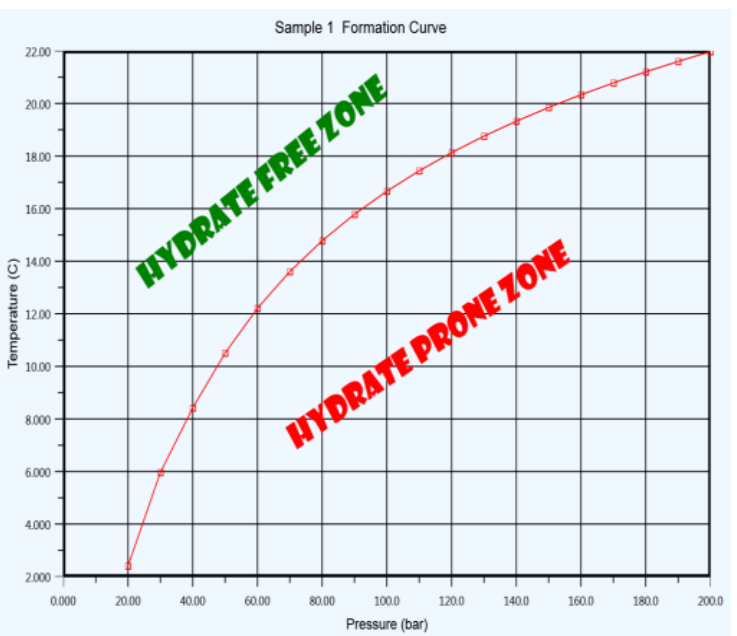

Fig 1. Hydrate formation curve with no inhibitor.

\section{B. Hydrate Formation Temperature with Methanol}

Similar simulation was performed as stated above with the addition of methanol as an inhibitor to prevent the formation of hydrate and the resulting output is shown below.

TABLE V: HYDRATE FORMATION TEMPERATURE WITH METHANOL

\begin{tabular}{lcc}
\hline State & $\mathbf{P}(\mathbf{B a r})$ & $\mathbf{T}\left({ }^{\mathbf{0}} \mathbf{C}\right)$ \\
\hline $\mathbf{1}$ & 0 & $-3.28 \mathrm{E} 4$ \\
\hline $\mathbf{2}$ & 10 & $-3.28 \mathrm{E} 4$ \\
\hline $\mathbf{3}$ & 20 & 0.11 \\
\hline $\mathbf{4}$ & 30 & 3.68 \\
\hline $\mathbf{5}$ & 40 & 6.16 \\
\hline $\mathbf{6}$ & 50 & 8.27 \\
\hline $\mathbf{7}$ & 60 & 10.01 \\
\hline $\mathbf{8}$ & 70 & 11.44 \\
\hline $\mathbf{9}$ & 80 & 12.67 \\
\hline $\mathbf{1 0}$ & 90 & 13.73 \\
\hline $\mathbf{1 1}$ & 100 & 14.67 \\
\hline $\mathbf{1 2}$ & 110 & 15.51 \\
\hline $\mathbf{1 3}$ & 120 & 16.27 \\
\hline $\mathbf{1 4}$ & 130 & 16.96 \\
\hline $\mathbf{1 5}$ & 140 & 17.60 \\
\hline $\mathbf{1 7}$ & 150 & 18.19 \\
\hline $\mathbf{1 8}$ & 160 & 18.75 \\
\hline $\mathbf{1 9}$ & 170 & 19.26 \\
\hline $\mathbf{2 0}$ & 180 & 19.74 \\
\hline $\mathbf{2 1}$ & 190 & 20.20 \\
\hline & 200 & 20.63 \\
\hline
\end{tabular}

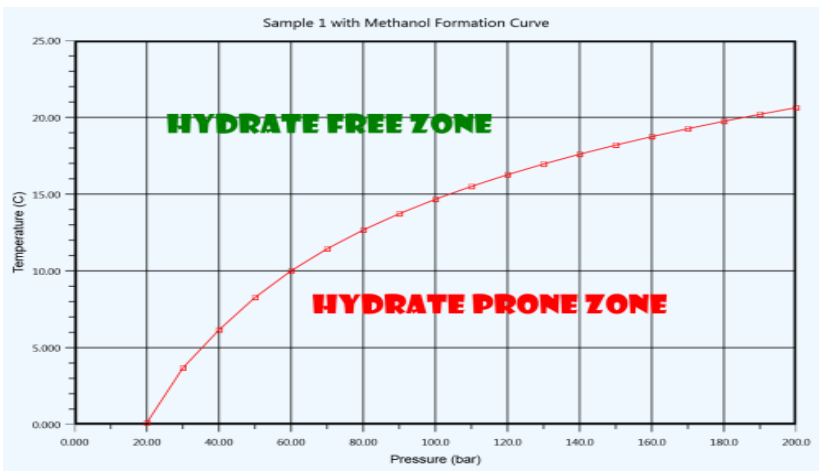

Fig 2. Hydrate formation curve with Methanol

C. Hydrate Formation Temperature with Ethylene Glycol

Also, Aspen-Hysys simulator was used to simulate the gas field parameters with ethylene glycol as an inhibitor to prevent or reduce hydrate formation temperature and the simulation result is shown below

TABLE VI: HYDRATE FORMATION TEMPERATURE WITH ETHYLENEGLYCOL

\begin{tabular}{lcc}
\multicolumn{3}{c}{ GLYCOL } \\
\hline State & P(Bar) & T( $\left.{ }^{\mathbf{0}} \mathbf{C}\right)$ \\
\hline $\mathbf{1}$ & 0 & $-3.28 \mathrm{E} 4$ \\
\hline $\mathbf{2}$ & 10 & $-3.28 \mathrm{E} 4$ \\
\hline $\mathbf{3}$ & 20 & 0.96 \\
\hline $\mathbf{5}$ & 30 & 4.52 \\
\hline $\mathbf{6}$ & 40 & 6.97 \\
\hline $\mathbf{7}$ & 50 & 9.05 \\
\hline $\mathbf{8}$ & 60 & 10.74 \\
\hline $\mathbf{9}$ & 70 & 12.12 \\
\hline $\mathbf{1 0}$ & 80 & 13.29 \\
\hline $\mathbf{1 1}$ & 90 & 14.28 \\
\hline $\mathbf{1 2}$ & 100 & 15.15 \\
\hline $\mathbf{1 3}$ & 110 & 15.92 \\
\hline $\mathbf{1 4}$ & 120 & 16.6 \\
\hline $\mathbf{1 5}$ & 130 & 17.22 \\
\hline $\mathbf{1 6}$ & 140 & 17.78 \\
\hline $\mathbf{1 7}$ & 150 & 18.30 \\
\hline $\mathbf{1 8}$ & 160 & 18.77 \\
\hline $\mathbf{1 9}$ & 170 & 19.22 \\
\hline $\mathbf{2 0}$ & 180 & 19.64 \\
\hline $\mathbf{2 1}$ & 190 & 20.03 \\
\hline & 200 & 20.4 \\
\hline
\end{tabular}

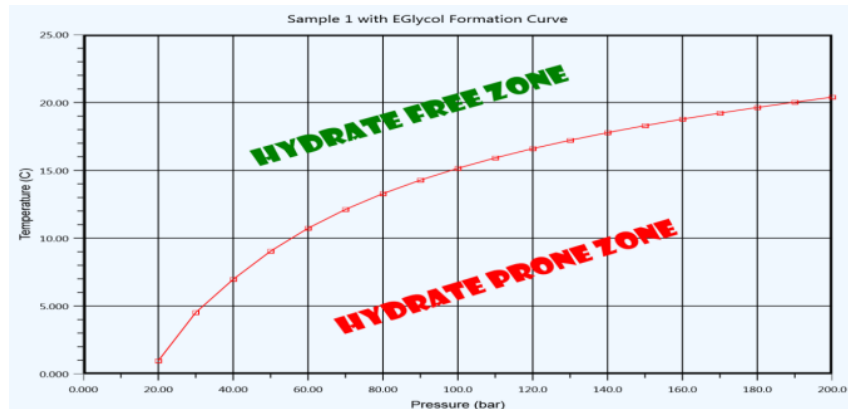

Fig 3: Hydrate formation curve with Ethylene glycol

\section{Hydrate Formation Temperature with Diethylene Glycol}

Diethylene glycol is added in this simulation operation as an inhibitor that mitigates hydrate formation and the resulting effect on hydrate formation temperature is shown thus 
TABLE VII. HYDRATE FORMATION TEMPERATURE WITH DIETHYLENE

\begin{tabular}{lcc}
\multicolumn{3}{c}{ GLYCOL. } \\
\hline State & $\mathbf{P}($ Bar $)$ & $\mathbf{T}\left({ }^{\mathbf{0}} \mathbf{C}\right)$ \\
\hline $\mathbf{1}$ & 0 & $-3.28 \mathrm{E} 4$ \\
\hline $\mathbf{3}$ & 10 & $-3.28 \mathrm{E} 4$ \\
\hline $\mathbf{4}$ & 20 & -0.32 \\
\hline $\mathbf{5}$ & 30 & 3.23 \\
\hline $\mathbf{6}$ & 40 & 5.67 \\
\hline $\mathbf{7}$ & 50 & 7.74 \\
\hline $\mathbf{8}$ & 60 & 9.42 \\
\hline $\mathbf{9}$ & 70 & 10.79 \\
\hline $\mathbf{1 0}$ & 80 & 11.95 \\
\hline $\mathbf{1 1}$ & 90 & 12.94 \\
\hline $\mathbf{1 2}$ & 100 & 13.79 \\
\hline $\mathbf{1 3}$ & 110 & 14.55 \\
\hline $\mathbf{1 4}$ & 120 & 15.23 \\
\hline $\mathbf{1 5}$ & 130 & 15.84 \\
\hline $\mathbf{1 6}$ & 140 & 16.39 \\
\hline $\mathbf{1 7}$ & 150 & 16.90 \\
\hline $\mathbf{1 8}$ & 160 & 17.38 \\
\hline $\mathbf{1 9}$ & 170 & 17.81 \\
\hline $\mathbf{2 0}$ & 180 & 18.23 \\
\hline $\mathbf{2 1}$ & 190 & 18.61 \\
\hline & 200 & 18.98 \\
\hline
\end{tabular}

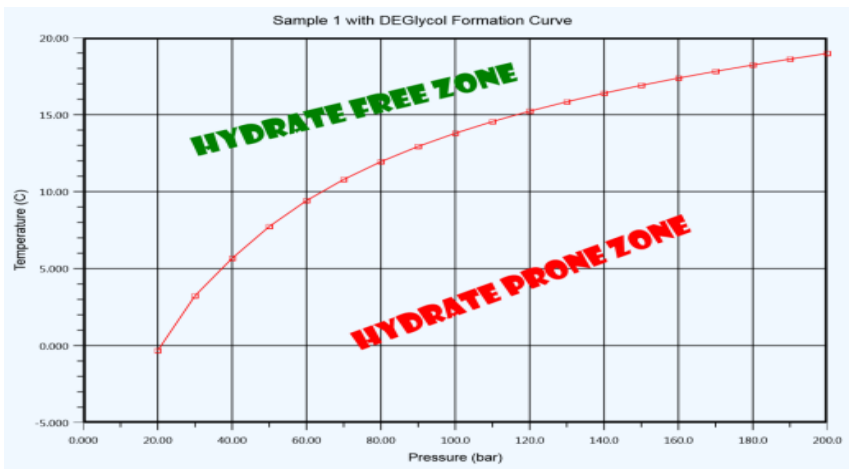

Fig 4: Hydrate formation curve with Diethylene glycol.

\section{E. Hydrate Formation Temperature with Triethylene Glycol}

In this scenario, triethylene glycol is used as an inhibitor in the simulation of hydrate formation temperature and the resulting outcome is given below.

TABLE VIII: HYDRATE FORMATION TEMPERATURE WITH TRIETHYLENE

\begin{tabular}{ccc}
\multicolumn{3}{c}{ GLYCOL. } \\
\hline State & P(Bar) & T( $\left.{ }^{\mathbf{0}} \mathbf{C}\right)$ \\
\hline $\mathbf{1}$ & 0 & $-3.28 \mathrm{E} 4$ \\
\hline $\mathbf{2}$ & 10 & 2.89 \\
\hline $\mathbf{3}$ & 20 & 8.07 \\
\hline $\mathbf{4}$ & 30 & 11.39 \\
\hline $\mathbf{5}$ & 40 & 11.97 \\
\hline $\mathbf{6}$ & 50 & 13.51 \\
\hline $\mathbf{7}$ & 60 & 15.47 \\
\hline $\mathbf{8}$ & 70 & 16.09 \\
\hline $\mathbf{9}$ & 80 & 16.55 \\
\hline $\mathbf{1 0}$ & 90 & 17.21 \\
\hline $\mathbf{1 1}$ & 100 & 17.76 \\
\hline $\mathbf{1 2}$ & 110 & 18.24 \\
\hline $\mathbf{1 3}$ & 120 & 18.66 \\
\hline $\mathbf{1 4}$ & 130 & 19.03 \\
\hline $\mathbf{1 5}$ & 140 & 19.38 \\
\hline $\mathbf{1 6}$ & 150 & 19.69 \\
\hline $\mathbf{1 7}$ & 160 & 19.99 \\
\hline $\mathbf{1 8}$ & 170 & 20.27 \\
\hline $\mathbf{1 9}$ & 180 & 20.54 \\
\hline $\mathbf{2 0}$ & 190 & 20.80 \\
\hline $\mathbf{2 1}$ & 200 & 21.05 \\
\hline & &
\end{tabular}

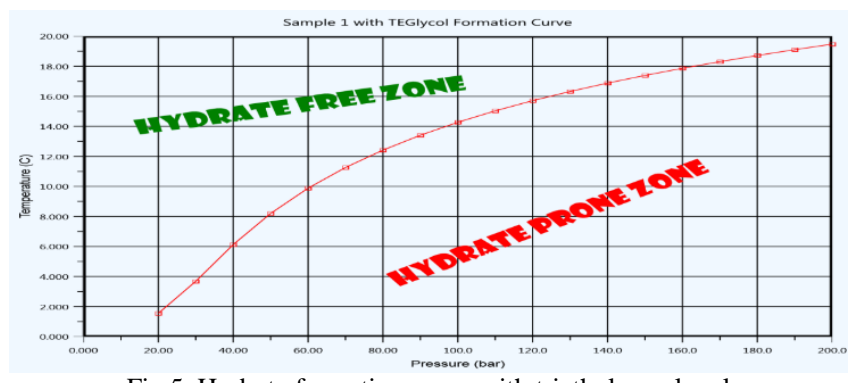

Fig 5. Hydrate formation curve with triethylene glycol.

\section{DISCUSSION}

Natural gas hydrate formation prevention through injection of chemical inhibitors have been a general practice in oil and gas industry as one of the techniques of mitigating hydrate formation, which is a hindrance or unwanted characteristic to flow and production in oil and gas industry. It can be deduced from this investigative study's simulation results that the introduction or injection of chemical inhibitors such as methanol, ethylene glycol, diethylene glycol and triethylene glycol leads to reduction of hydrate formation temperature at any specified operating pressure. This allows constant and adequate flow of gas within the system as flow assurance issues are mitigated against. It can be inferred from the study that the injection of any chemical inhibitor into the process, the hydrate formation temperature increases down the operational state as pressure increases with triethylene glycol yielding the highest hydrate formation temperature at 200bar.

Based on the determined study's data highlighted above and comparing hydrate formation temperatures with no inhibitor and chemical inhibitors, methanol as a chemical inhibitor gives the least hydrate formation temperature at any operating pressure in comparison with ethylene glycol, diethylene glycol and triethylene glycol respectively. In addition, methanol inhibitor shows the highest reduction deviation from the hydrate formation temperature process with no inhibitor with $95.5 \%$ deviation.

\section{CONCLUSION}

Hydrate formation is a serious flow assurance problem in oil and gas industry and its prevention or mitigation is of utmost importance to the industry for efficient flow and production operations. It can be deduced from this investigative study that hydrate formation prevention by chemical inhibitors is a mean of mitigating against flow assurance difficulties in oil and gas industry. Also, this study shows that application of chemical inhibitors methanol, ethylene glycol, diethylene glycol and triethylene glycol prevents hydrate formation by reducing hydrate formation temperature. In addition, it is also worthy to note that this investigative study did not account for the quantity or amount of different chemical inhibitors injected but with the application of Hammer Schmidt equation, the weight percentage range of chemical inhibitors is between 20-25 weight percent for methanol and 60-70 weight percent for glycols respectively. 


\section{NOMENCLATURE}

MeOH: Methanol

MEG: Monoethylene glycol

DEG: Diethylene glycol

TEG: Triethylene glycol

SG: Specific gravity

Yi: Mole fraction of component $\mathrm{i}$

Mw: Molecular weight

$\Delta T:$ Temperature of depression

M: Molecular weight of inhibitor

C: Physical constants of inhibitor

W: Weight percent of inhibitor

MWair: Molecular weight of air

P: Pressure

T: Temperature

CH4: Methane

C2H6: Ethane

C3H8: Propane

i-C4H10: Isobutane

C4H10: Butane

i-C5H12: Isopentane

C5H12: Pentane

C6H14+: Hexane plus
CO2: Carbondioxide

N2: Nitrogen gas

\section{REFERENCES}

[1] E.D. Sloan Jr, Clathrate hydrates of natural gases, 2nd ed, Marcel Dekker Incorporated, New York, USA, 1998.

[2] C. John, Natural gas hydrates: A guide for engineers, 2nd ed, Elsevier incorporated, 2009.

[3] E.D. Sloan Jr, and C. Koh, Clathrate hydrates of natural gas, 3rd ed, CRC pressBoca Raton, 2007

[4] Skovborg P., Rasmussen P. and Mohn, U, Measurement of induction times for the formation of methane and ethane gas hydrates. Chemical Engineering science, 1993, 48(3), 445-453

[5] A.A. Kaczmarski, and S.E. Lorimer, "Emergence of Flow Assurances as a Technical Discipline Specific to Deepwater: Technical Challenges and Integration into Subsea System Engineering", presented at Offshore Technology Conference, Houston, Texas, April 30 - May 3, 2011.

[6] M.A. Kelland, History of the development of low dosage hydrate inhibitors Energy Fuels, 2006, 20(3), 825- 847 DOI: 10.1021/ef05427x

[7] S.O. Ogezo, Effect of Ethylene-Glycol on Hydrate Formation in gas pipeline, A Case Study of Eriemu Field", MSC dissertation, Dept of Gas Engineering Management, University of Salford, Manchester, England, 2014

[8] L.O. Owodunni and J.A. Ajienka, Use of thermal insulation to prevent paraffin wax deposition, Society of Petroleum Engineer 1190, 2007. 